\title{
Universalidade e crise das universidades
}

\author{
Simon Schwartzman
}

\section{Introdução}

O ensino superior é muito diferente hoje, em todo o mundo, do que era apenas vinte ou trinta anos atrás ${ }^{1}$. Tudo é muito maior, mais complexo, mais caro, mais contraditório. Além disto, existem diferenças profundas entre culturas e sociedades. Uma palavra, no entanto - Universidade - parece permanecer constante no espaço e no tempo. A universalidade das instituições universitárias se explica, em parte pelo menos, pelo fato de que elas desempenham papéis similares em todas as sociedades, relacionados com a existência de instituições e pessoas dedicadas à criação, manutenção e transmissão da cultura escrita e sistematizada. É esta universalidade, por sua vez, que explica e justifica o interesse intelectual e a profundidade da chamada questão universitária.

$O$ objetivo deste texto é tratar de identificar quais são estes elementos em comum, a partir de uma visão a respeito dos papéis mais permanentes e originais das instituiçóes de ensino superior no mundo moderno, e de sua evolução e transformação no mundo de hoje. Ele busca mostrar que existem coisas comuns a todos os sistemas de ensino superior, tanto do ponto de vista de suas funções quanto de suas eventuais tensōes e dificuldades; e que as diferenças profundas que também existem são inteligíveis a partir de um marco conceitual comum. De fato, o que diferencia uma sociedade de outra, deste ponto de vista, é a forma pela qual estas tensões e dificuldades foram enfrentadas e processadas. Existe um momento crucial na história dos países em que suas instituições mais importantes devem ser modernizadas e transformadas, e a maneira pela qual esta transição é feita vai ter importantes conseqüências no destino futuro do país. É clássica, e bastante conhecida, a tese de Barrington Moore (1966) sobre os efeitos da modernização da agricultura, ou seu fracasso, sobre a formação dos estados contemporâneos. $O$ texto sugere que algo semelhante pode ser dito dos sistemas de ensino, e do ensino superior em particular.

\section{Caciques e Pajés}

Todas as sociedades apresentam um potencial de disputa entre lideranças políticas, estabelecidas pela via da ação militar, ou do poder pátrio, e lideranças de tipo intelectual ou moral, estabelecidas pelo acesso privilegiado ao conhecimento, seja ele de origem religiosa, mágica, medicinal, ou outra ${ }^{2}$. Esta disputa milenar entre caciques e pajés não $\epsilon$, no entanto, uma disputa à morte. Freqüentemente, no passado, lideranças políticas, intelectuais e espirituais atuaram unidas e inseparáveis. Em Estados teocráticos, como no Egito antigo ou no

1 Este texto é uma versão revista da conferência feita ao "Seminário Internacional sobre Educação Superior: criatividade, legitimação e transformações dos sistemas de ensino superior", organizada pela Diretoria Nacional de Universidades e Escolas Superiores da Suécia em Rosenōn, Dallarõ, 1-5 de junho de 1987.

2 Estas idéias estão contidas, de forma muito mais elaborada e complexa, em Economia e Sociedade, de Max Weber. (diversas edições). 
Tibet, o líder político é a própria encarnação da divindade, e a organização eclesiástica não se distingue da administração da coisa pública. Sociedades puramente teocráticas, no entanto, foram raras mesmo na Antiguidade.

O surgimento de tradições religiosas e procedimentos administrativos escritos tende a fazer do acesso ao conhecimento uma especialidade, à qual se associa um estilo de vida próprio, freqüentemente ascético e exemplar, que serve para justificar as pretensóes à autoridade moral e ao exercício do poder dos sacerdotes e escribas sobre a sociedade como um todo. Esta pretensão à liderança se confronta, desde início, com as lideranças de tipo carismático ou mágico, que pretendem ter um acesso direto e imediato às verdades mais profundas pela via da revelação ou dos dons inatos, sem passar pelo crivo da educação e do aprendizado. Ela se confronta, também, com o poder que se estabelece por outras vias - a conquista militar, o acúmulo de riquezas pelo comércio -, mas às quais faltam os princípios de legitimidade moral e intelectual. Se estas tendências muitas vezes conflitam, muito freqüentemente, também, elas se aliam - a Igreja se associa ao Estado, os religiosos educam os filhos dos reis e dos nobres, e ambos cooperam para manter a sociedade como um todo estável e respeitosa das autoridades temporais e espirituais. Têm razão, pois, os que vêem nas organizações, instituições e pessoas dedicadas à administração do conhecimento aliados freqüentes dos que detêm o poder temporal -, mas se enganam os que acham que esta é uma aliança simples, automática e inquebrantável.

De fato, assim como o conhecimento é uma forma de poder e controle social, ele também funciona como uma via de mobilidade social, rebeldia e revolução. A história está cheia de exemplos de sistemas de dominação estabelecidos, que se vêem desafiados por novos grupos que trazem consigo idéias, conhecimentos e interpretações do mundo, das coisas e dos homens, que se confrontam com aqueles do poder. Seria simplista, evidentemente, interpretar estes movimentos somente como disputas por idéias, já que, junto a elas, vem geralmente todo um conjunto de atividades de tipo econômico, militar e social que buscam sua legitimação. O exemplo clássico moderno é o da reforma protestante, que se desenvolve no ímpeto da revolução capitalista e burguesa; outro exemplo atual é a associação entre o islamismo fundamentalista e o nacionalismo árabe, assim como o revivalismo ortodoxo judaico.

\section{As Instituições mais Antigas}

As universidades modernas têm muito em comum com todos estes fenômenos de abrangência histórica tão universal. Dizem que universidades e igrejas são as instituições mais antigas que existem, e isto não pode ser simples coincidência. De fato, universidades e igrejas compartem algumas características importantes: ambas proclamam ser o repositório das formas mais elevadas do conhecimento, cultivado zelosamente pelos iniciados, que são por isto admirados, respeitados e invejados pelos demais. $O$ conhecimento que proclamam ter não é somente prático e útil (ainda que a ciência, o milagre e a mágica tenham certamente sua utilidade), mas, principalmente, consiste no acesso às verdades consideradas mais profundas e fundamentais, qualquer que seja o sentido que se atribua, em cada sociedade e em cada era, a estas palavras. É um tipo de certeza em um mundo incerto e inseguro, que só pode ser vislumbrado de longe pelos que estão fora.

Pertencer a este círculo fechado, onde a Verdade é codificada e transmiti-

De fato, assim como o conhecimento é uma

forma de poder e controle social, ele também funciona como uma via de mobilidade social, rebeldia e revolução. da, pode significar prestígio, autoridade, e, muitas vezes, poder e riqueza. Nem todos conseguem chegar lá. Universidades e igrejas conseguem combinar as formas mais extremas de universalismo e seletividade. Todos podem participar, todos são chamados - desde que tenham as qualidades necessárias. O valor de cada um deve ser estabelecido por atos e palavras, e, quando os atos não existem, ou são difíceis de precisar, as palavras - e, principalmente, os rituais - devem estabelecer a ponte entre o eleito de hoje e as tradições que remontam a 
certezas inquestionáveis do passado, tanto mais inquestionáveis quanto mais antigas. Riuuais de passagem marcam a entrada e a safda dos eleitos no mundo do conhecimento; rituais diários de leitura e estudo, e o uso apropriado de certas expressōes e palavras, que os leigos não entendem, assinalam a socialização bem feita dos jovens ao círculo fechado dos velhos e sábios. Os rituais servem, tambem, para proteger as universidades e igrejas da intervençảo externa; e sua pretensão ao conhecimento supremo faz com que estas instituições tendam ao monopolio intelectual, e não aceitem com facilidade os ideais de uma epistemologia pluralista.

Esta descrição $€$ um tipo ideal ${ }^{3}$, ou caricatura, de instituições que parecem existir em todas as sociedades de linguagem escrita e conhecimentos codificados. No mundo real, evidentemente, existem universidades e religiōes as mais variadas, e as características que desenvolvem para assegurar sua estabilidade e longevidade - 0 culto da tradição, a luta pela autonomia e auto-regulação, 0 monop6́lio da Verdade, a organização burocrática, o comportamento ritualizado - nem sempre alcançam seus objetivos. Universidades, tanto quanto as igrejas, estão sujeitas a conflitos e tensóes, com mudanças em seus objetivos e em seus membros, e disputas sobre a validade de suas tradiçóes passadas e a legitimidade de seus representantes atuais.

Tipos ideais sâo úteis porque ajudam a identificar as questōes que motivam as pessoas e levam ao conflito e às transformações; no nosso caso, eles nos ajudam a entender o fascínio que sempre esteve presente no estudo das religiōes e das instituiçōes de ensino superior. Para os intelectuais, o estudo destas instituições $\epsilon$ inseparável de sua propria busca de identidade e reconhecimento social. Instituiçōes que lidam com os valores e os conhecimentos mais elevados lidam tambem, acredita-se muitas vezes, com o proprio destino de suas sociedades: como os homens devem ou podem lidar com a natureza e com outros homens, como devem lidar com o desconhecido, que tipo de autoridade devem aceitar ou rejeitar, que hierarquias sociais são legítimas ou não. Seria ingênuo acreditar que tudo o que ocorre no mundo encantado das igrejas e das universidades ocorre também no mundo real; mas seria também ingênuo pensar que universidades e igrejas não seriam senão a sombra, ou reflexos, de outras realidades.

\section{Universidades e Igrejas: proximidade e conflito}

$O$ fato de universidades e igrejas cumprirem funçôes similares explica muito de sua proximidade e de seus conflitos. Na Idade Média, assim como nos impérios espanhol e português nos séculos XVI e XVII, a Igreja dominava completamente, e as universidades não passavam de instituiçōes de ensino a seu serviço, e por isto mesmo intelectualmente pouco interessantes.

Mesmo nestas condiçōes, no entanto, surgem conflitos sobre pretensóes alternativas de autoridade em matéria religiosa, burocrática e acadêmica, disputas estas que frequientemente buscam apoio fora dos muros da academia. A própria existência de um sistema educacional à parte da organização eclesiástica faz supor que os conhecimentos desenvolvidos e transmitidos pela corporação religiosa tenham se tornado insuficientes para alguns setores da sociedade. Estabelecidas na transição da Época medieval para o período renascentista, as primeiras universidades européias eram, em essência, corporaçōes de estudantes e professores que buscavam conseguir, muitas vezes a duras penas, o direito ao trabalho intelectual independente, a autonomia administrativa e mesmo o direito a foro especial para seus membros, em relação as autoridades eclesiásticas e polf́ticas de então. As primeiras universidades se dedicavam ao ensino das pro-

As universidades nos países ocidentais evoluíram, de pequenos apêndices da Igreja, para se constituírem na principal instituição para o processamento do conhecimento do mundo moderno.

${ }^{3}$ Um tipo ideal, em linguagem sociológica, é uma representação conceitual estilizada, onde as características mais marcantes de um fenômeno social são acentuadas. Ideal, aqui, se refere a idéia, conceito, e não a ideal como modelo a ser buscado ou conseguido. 
fissōes liberais da época (teologia, direito canônico, medicina), que era precedido pelas chamadas disciplinas propedêuticas, o trivium (gramática, retórica e lógica) e o quatrivium (geometria, aritmética, música e astronomia), que em conjunto formavam as sete artes liberais, reunidas, como em Paris, em uma Faculdade Inferior. Na pratica, no entanto, as artes liberais assumiam freqüentemente mais importância dentro das universidades do que o ensino profissional, propiciando um desenvolvimento cultural e intelectual no interior das universidades que nem sempre se acomodava com facilidade ao dogma da identidade entre a verdade conhecida pela via racional e a verdade religiosa, que era $o$ fundamento legitimador da coexistência entre as universidades e a Igreja.

Em outras palavras, as universidades europeias cristalizaram o surgimento e a diferenciação de uma nova forma de organização para o conhecimento, de tipo secular, de base racional, produzido por uma comunidade freqüentemente cosmopolita, ciosa de sua independência em relação aos poderes locais, assim como de seus direitos e autonomia. Ao valorizar acima de tudo o uso da razão e a competência intelectual, as universidades inevitavelmente se chocam com a autoridade da Igreja que se baseia, sobretudo, na autoridade constituída segundo a tradição e o dogma. Por isto, as universidades sempre foram terreno fértil para heresias e secessōes, e serviram de terreno para os conflitos entre Estado e Igreja que marcaram o desenvolvimento dos estados nacionais contemporâneos.

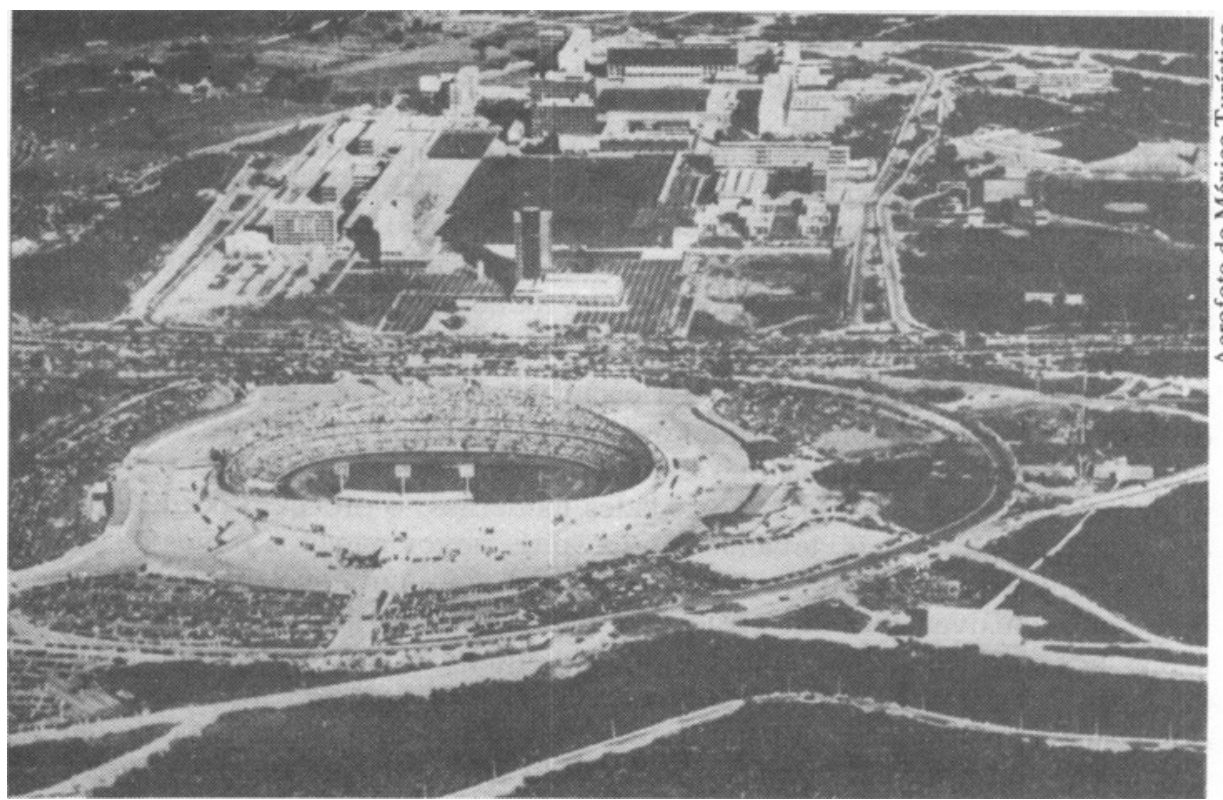

As universidades nos países ocidentais evoluíram, de pequenos apêndices da Igreja, para se constituírem na principal instituição para o processamento do conhecimento do mundo moderno. A separação, e eventual supremacia, das universidades em relação à Igreja, foi um processo difícil, que se deu de forma diferente de uma sociedade para outra, e que produziu resultados também distintos. A Igreja Católica lutou longa e bravamente por sua supremacia, e ainda não desistiu. O Vaticano mantém sua própria Academia de Ciências, e universidades católicas existem em todo o mundo. As religiōes protestantes, de uma maneira geral, aceitaram a supremacia do conhecimento leigo em matérias deste mundo, e tendem a se limitar às questóes da fé individual, moralidade pessoal e das verdades de foro íntimo. O renascimento do fundamentalismo religioso, no entanto, principalmente nos Estados Unidos, e as disputas legais sobre o ensino do evolucionismo e do creacionismo nas escolas públicas, mostram que esta aceitaçāo está começando a ser revista por muitos.

A história das universidades européias dos últimos duzentos anos, que seria evidentemente impossível resumir aqui, gira ao redor de alguns conflitos 
e tensōes básicas. Por uma parte, é a tensão entre as tendências a transformá-las em simples mecanismos de formaçăo profissional, segundo critérios definidos externamente a elas, e as aspiraçōes freqüentemente mais altas dos que passam pelas novas formas de estudo propedêutico e ou aí ficam, muitas vezes, como sacerdotes de um novo tipo de conhecimento. Depois, $\epsilon$ o conflito que se estabelece entre as formas mais tradicionais e estabelecidas de cultura, baseadas no conhecimento das artes liberais e no acesso aos clássicos gregos e latinos, e as novas formas de conhecimento que ganham força junto ao desenvolvimento da ciência experimental e da crença no valor da convicção subjetiva e íntima, em contraposição ao predomínio da autoridade. Estes conflitos ressurgem em roupagens modernas no confronto entre o desejo de fazer das universidades centros de reflexão e pesquisa científica autônomos e independentes, e a tentativa de transformá-las em centros de formação especializada para atender, tão eficientemente quanto possível, às demandas de profissionais especializados para a gestāo econômica, política e administrativa das sociedades modernas.

A generalização da chamada educação de terceiro grau nos dias de hoje faz com que os conceitos mais clássicos de universidade se diluam, aparentemente, em um sistema educacional muito mais amplo e complexo do que jamais tenha existido. No Brasil, fala-se hoje de sistema universitário para se referir a todas estas instituiçőes. Ainda que exista formalmente uma distinção entre universidades e estabelecimentos de ensino isolados, na prática esta é uma questão meramente burocrática, e não há diferença legal ou social entre títulos emitidos por um outro tipo de instituição. Diante de fatos como este, não seriam as universidades tradicionais fenómenos passados e ultrapassados? Em que medida pensar sobre as universidades medievais, a universidade alemã no século XIX, ou mesmo sobre os ideais que presidiram a formação da Universidade de São Paulo na década de 30 , nos ajuda a entender e a propor algo que faça sentido para os problemas da educação superior no mundo atual?

A razão pela qual o passado nos ajuda a entender o presente é que os sistemas educacionais contemporâneos estão sujeitos aos mesmos fenômenos de disputa entre os princípios de liderança política e os princípios de liderança intelectual, moral e espiritual que caracterizavam as sociedades do passado. A principal diferença $\epsilon$ que, nas sociedades modernas, o processo de racionalização avançou muito mais, levando à criação de novos papéis e fontes de solidariedade e liderança. A revolução burguesa consagra um novo tipo de liderança, baseada exclusivamente em posiçōes conquistadas no mercado de trocas, que são as lideranças de cunho econômico enquanto tal; e a revolução política que a acompanha gera novas formas de liderança política, que se estabelecem dentro dos sistemas partidários e eleitorais, e se firmam como um componente central das novas formas de dominação política de base racional-legal. A separação iniciada pelas universidades tradicionais entre o conhecimento religioso, sagrado e revelado, e o conhecimento de base racional, é levado ao extremo pelo desenvolvimento das ciências naturais de base experimental, que tratam de se instituir como uma nova filosofia natural, legitimadora e instrumentadora do individualismo, do racionalismo, da ordem democrática e da revolução industrial burguesa. Além disto, as sociedades modernas propiciam o desenvolvimento de sistemas organizacionais cada vez mais complexos, de tipo governamental ou privado, que exercem um controle de tipo técnico, ou administrativo (na realidade, tecnocrático) sobre grupos sociais cada vez maiores. Estas novas formas de liderança, dominação e participaçāo social não eliminam, no entanto, as antigas: a Igreja continua a existir e a desempenhar seu papel em suas diversas formas; o poder político de base militar não se subordina com facilidade às instituiçōes políticas de base racional-legal; e os antigos. mecanismos de liderança e dominaçāo baseados na nobreza, na língua, na nacionalidade e na raça não se desfazem com tranqüilidade, mostrando, na realidade, surpreendente vitalidade ante $o$ assédio sistemático dos processos de racionalização das sociedades modernas.
A generalização da chamada educação de terceiro grau nos dias de hoje faz com que os conceitos mais clássicos de universidade se diluam, aparentemente, em um sistema educacional muito mais amplo e complexo do que jamais tenha existido. 


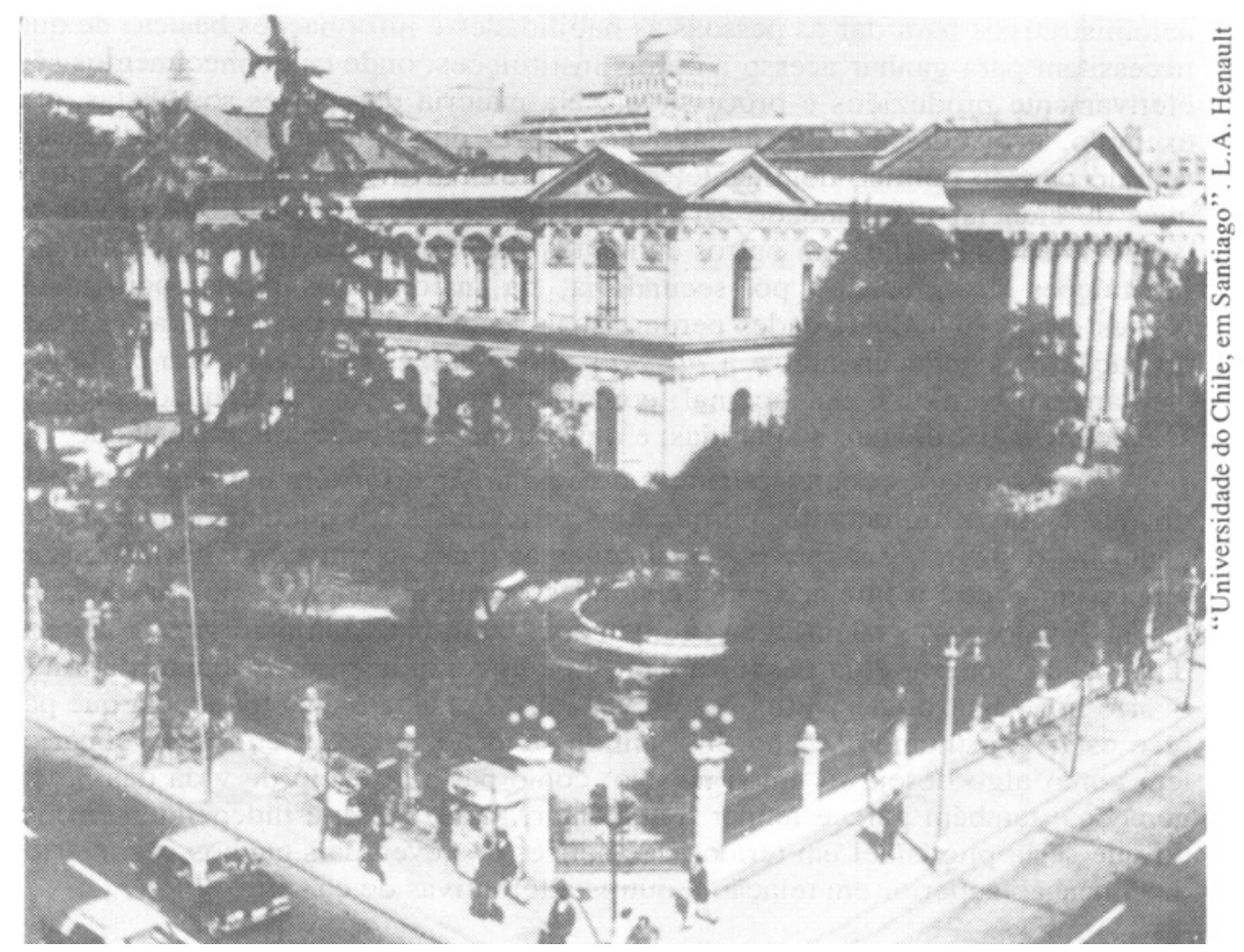

As maneiras pelas quais a educação superior é organizada hoje - o tamanho relativo do setor público, a autonomia que as universidades possuem ou nāo, a distância que elas mantêm - ou não - das igrejas, partidos polf́ticos e outras instituiçỏes - tudo isto tem a ver com a forma pela qual estes antigos conflitos foram encaminhados.

\section{Conhecimentos Úlimos vs. Conhecimentos Práticos}

O resultado dos conflitos entre Universidade e Igreja nas sociedades ocidentais foi uma divisão kantiana de trabalho: as universidades cuidariam do conhecimento empírico valorativamente neutro, enquanto que a Igreja cuidaria dos valores e das verdades mais profundas e substantivas.

Esta divisão do trabalho explica muito do extraordinário sucesso das universidades ocidentais desde, pelo menos, o início do século XIX. Livres de dogmas inquestionaveis e controles externos, as universidades tradicionais abriram gradualmente seus muros para o conhecimento cientifico e técnico, e lhe proporcionaram um terreno fértil para crescer e se desenvolver. Este arranjo funcionou tanto melhor porque, na realidade, ninguem acreditava realmente nele. Racionalismo, evolucionismo, e empirismo foram idéias poderosas na formação das universidades modernas, e se constituíam em autênticas alternativas filosóficas às verdades consagradas pelos dogmas religiosos. Igrejas e movimentos religiosos jamais abdicaram de seu desejo de estar presentes e influenciar a vida quotidiana das instituiçōes universitárias, e, quando isto se tornou de todo impossível, criaram suas próprias instituiçóes.

A situação contemporânea, evidentemente, e muito mais complexa, porque existem muito mais participantes. O conhecimento científico, tecnologico e social é produzido hoje em muitas outras instituiçōes, além de igrejas e universidades, e os mercados para sua difusão e decantação são também outros - sociedades científicas, revistas especializadas, mercados de tecnologia, escritórios de registro de patentes. Em algumas situaçōes mais extremas, as instituiçóes contemporâneas de ensino superior se transformam em simples mecanismos 
administrativos para dar às pessoas as habilidades e informações básicas de que necessitam para ganhar acesso a outras instituições, onde os conhecimentos são efetivamente produzidos e processados. Na maioria dos países socialistas, por exemplo, a elaboração das formas mais nobres de conhecimento é atribuição, seja do partido político dominante, seja na área científica e técnica, das academias de ciência, não cabendo às universidades senão o papel de transmitir os conhecimentos gerados em outros contextos. Isto também ocorre na maioria das instituições de educação pós-secundária, na maioria dos países ocidentais. Nestes casos, as universidades perdem suas funções clássicas de geração e codificação do conhecimento, e a questão universitária se reduz a um problema estritamente técnico e operacional: como formar um número adequado de pessoas, com as habilidades requeridas, e a um custo razoável para a sociedade.

As instituiçōes contemporâneas de ensino superior têm um interesse mais do que técnico, no entanto, porque elas dificilmente se deixam reduzir a este papel instrumental, por razóes semelhantes às quais as universidades antigas se rebelavam contra a Igreja: as universidades recrutam talento, e pessoas acostumadas a valorizar o talento não aceitam com facilidade outras formas de autoridade. Uma boa parte da pesquisa científica e tecnológica mais avançada ainda ocorre hoje dentro de instituições universitárias, e esta é uma tendência que parece estar aumentando, e nāo diminuindo. $\mathrm{E}$ o apelo que a educação superior tem como algo desejável em si mesmo, como parte do ciclo de vida das novas gerações, também parece tender a aumentar, muito além, e independentemente do que seria previsível em termos de análises dos eventuais ganhos pecuniários da educação superior em relação a outras alternativas de carreira.

\section{Monopólio, Meritocracia e Hierarquia}

No passado, as instituições educacionais controladas pela Igreja eram a única forma pela qual uma pessoa poderia ter acesso aos conhecimentos codificados de sua sociedade e, assim, aos privilégios e prestígio social a eles associados. Este monopólio era mantido, paradoxalmente, por mecanismos meritocráticos e, pelo menos em princípio, igualitários. Se todos querem atingir os mesmo objetivos, e concordam com a validade dos mecanismos de acesso a estes objetivos, esta é a melhor maneira de validar o prestígio e a autoridade dos que conseguiram chegar ao topo. Assim, o princípio democrático da meritocracia não somente fortalecia o monopólio, como também contribuía para a manutenção da hierarquia.

O controle monopolístico do conhecimento e da educação não servia somente para garantir vantagens e privilégios para alguns, mas funcionava também como mecanismo de manutenção da solidariedade social e de seu controle. Estas funçōes não teriam como se manter com a divisão kantiana, que gerou a educação laica e aparentemente separada do mundo dos valores. Não é por acaso que o surgimento das sociedades modernas foi acompanhado por todo um pensamento de tipo conservador que buscava e pregava a volta a um passado medieval mítico onde o poder espiritual e o poder temporal se mantinham indissolúveis sob a tutela moral da Igreja, à qual se subordinavam a atividade econômica, o sistema educacional, a vida política e as instituições militares. Menos radicais, os sociólogos da chamada linha funcionalista, de Émile Durkheim a Talcott Parsons, dedicaram sua obra à busca dos princípios unificadores que pudessem manter a coerência e garantir a estabilidade social dentro da multiplicidade e da diferenciação. Para Durkheim, era exatamente ao sistema educacional que caberia este papel integrador, pela transmissão de valores de coesão e integração social em uma sociedade moderna e laicizada. Para Parsons, o sistema social tenderia ao equilíbrio graças aos valores básicos transmitidos pelos sistemas integrativos da sociedade - de novo a educação.

É curioso como, em certo sentido, os ideais de Durkheim e Parsons se materializaram. De fato, os sistemas universitários nas sociedades industriais e 
pós-industriais de hoje ainda mantêm grande parte de sua estrutura hierarquizada e de sua pretensâo ao controle monopolístico da cultura superior. $O$ estado da Califórnia, nos Estados Unidos, talvez seja um exemplo extremo. Por uma parte, o ensino superior naquele estado $e$ totalmente aberto e, de fato, ao alcance de quem quiser. Por outra parte, as instituiçōes de ensino superior da Califórnia são estritamente hierarquizadas em termos de prestígio, autonomia, volume de recursos e qualidade dos alunos, com a Universidade da Califórnia no topo e os community colleges na base. Anos de críticas, às vezes radicais, contra as conseqüências socialmente regressivas desta estratificação não tiveram o menor efeito; continua a haver um forte consenso a respeito de em que mãos o controle das formas mais elevadas de produção e transmissão do conhecimento devem estar. Na Califórnia (como no Japão, outro sistema fortemente hierárquico de ensino superior), o monoṕ́lio é mantido pelo princípio meritocrático, que coloca a culpa do fracasso nos indivíduos, antes que no sistema social que os exclui.

Este resultado traz, evidentemente, tensões, e outras sociedades resolveram o problema de outra maneira, ou simplesmente não conseguiram resolvê-lo. Homens de negócios, políticos e militares em todas as sociedades sempre resistiram às pretensões hegemônicas dos intelectuais do mundo acadêmico, e desenvolveram sistemas alternativos de valores e verdades últimas, baseados em virtudes como o patriotismo, a força pessoal, o espírito prático e empreendedor, o sentido comum, a coragem e a esperteza. $O$ antiintelectualismo, quando pode, trata de impor seus valores às instituições de ensino superior, seja pela imposição de certos conteúdos (como foi o caso, no Brasil, da Educação Moral e Cívica), seja pela implantação de sistemas educacionais alternativos, de cunho prático e aplicado, seja, finalmente, pelo ataque direto aos princípios meritocráticos das universidades. A criação de quotas positivas ou negativas para determinados grupos raciais e econômicos, os ataques generalizados aos sistemas de seleção e avaliação de estudantes e professores são outras tantas formas de assédio às pretensões hegemônicas das universidades.

Somente em sociedades pequenas e ricas, como as dos países do norte da Europa, é possível tentar combinar de forma adequada os princípios do mérito com a igualdade social efetiva. Em outras sociedades, a tentativa de juntar estas duas coisas leva ao prejuízo de ambas. As universidades latino-americanas são todas iguais perante a lei, e em muitos países os princípios meritocráticos foram totalmente abolidos e substituídos por sistemas de livre matrícula e pela baixa geral de padrões para a aprovação de alunos nos cursos e outorga de diplomas. Em muitos casos, o princípio do mérito não é efetivamente abolido, mas transferido para outros lugares e instituiçōes - cursos de pós-graduação, instituiçōes privadas, ou, seguindo o modelo francês, para escolas especializadas e colocadas estrategicamente fora do alcance do sistema de ensino superior massificado. Em alguns casos extremos, como na Revolução Cultural chinesa e em alguns dos países muçulmanos mais radicais de hoje, todos os valores associados ao conhecimento codificado e ao valor da educação são substituídos por outros princípios e valores de cunho religioso ou político. Quando isto ocorre, os sistemas universitários são, na prática, destruídos.

No passado, as instituiçōes educacionais controladas pela Igreja eram a única forma pela qual uma pessoa poderia ter acesso aos conhecimentos codificados de sua sociedade e, assim, aos privilégios e prestígio social a eles associados.
O fato de que, nas modernas sociedades, conhecimentos sejam constantemente produzidos e reproduzidos fora das universidades, e até mesmo fora dos sistemas de educação e pesquisa científica formalmente estabelecidos, poderia levar à conclusão de que pouco resta, nas universidades de hoje, das antigas pretensões ao monopólio ou hegemonia em relação às formas mais elevadas de conhecimento. No entanto, estes desenvolvimentos paralelos raramente levam a questionar o papel desempenhado pelas universidades nas sociedades modernas, e as demandas por educação superior e pesquisa universitária parecem aumentar continuamente. Neste sentido, a hegemonia das universidades em relação às formas superiores de conhecimento parece ser maior hoje do que nunca. 
O princípio meritocrático nunca significou que o acesso estivesse, de fato, aberto a todos. Restriçōes formais e informais sempre existiram de um modo ou outro - numerus clausus, restriçōes religiosas, raciais e nacionais, taxas, dotes, patronagem. Poder competir bem em sistemas meritocráticos dependeu sempre de um nível prévio adequado de educação formal ou informal, o que é, por sua vez, funçāo do ambiente familiar e de um investimento prévio em educação. Estes aspectos perversos, ou regressivos, da educação têm sido objeto de estudos e demonstrações detalhados, que ganharam grande popularidade nas últimas décadas.

O que tem sido menos analisado é como que esta nova percepção da educação, como mais um instrumento de estratificação social e desigualdade, surgiu após um longo período em que a educação era entendida exatamente como seu oposto, ou seja, como um instrumento de progresso social, democracia e igualdade. Teria sido esta uma simples ilusão, agora desmascarada pelos pesquisadores contemporâneos? Na realidade, não. A expansão da educação moderna de fato coincidiu com a expansão da mobilidade social em todas as partes. Muitos autores interpretaram isto como significando que a educação criava, por ela mesma, novos produtos e novas oportunidades de trabalho. Para eles, a educação passou a ser vista como um investimento econômico de grande rentabilidade, e possível de ser medido pelas suas taxas de retorno, ou seja, estimativas de renda gerada pela educação em relação a seus custos. Esta visão da educação como capital humano é fartamente comprovada por evidência originada das nações industrializadas, mas leva a resultados estranhos e paradoxais quando transferida para contextos como a Índia, África ou América Latina, onde as instituições educacionais se expandiram com grande rapidez e de forma independente de uma expansão correspondente do setor industrial. Nestas sociedades, é ainda possível detectar benefícios econômicos para o investimento individual em educação, que de fato são freqüentemente maiores do que nos países industrializados. Mas, nelas, o acesso à educação é muito mais restritivo e dependente de recursos sociais e econômicos prévios, e a soma dos benefícios individuais não se traduz em benefícios para a sociedade como um todo. Para estas sociedades, a visão cética da educação, desenvolvida por autores como Randall Collins, Pierre Bourdieu e Raymond Boudon ${ }^{4}$, parece a mais apropriada: o que a educação formal proporciona é, principalmente, status, credenciais e oportunidades para monopólios profissionais e sinecuras.

Houve quem tentasse esclarecer esta questão distinguindo entre a educação como investimento produtivo (como, por exemplo, em engenharia) e a educação como consumo (como, por exemplo, em literatura, dança ou ciências sociais). A maioria dos produtos da educação, no entanto, só pode ser vendida ou utilizada por outros como serviços, e se determinado serviço (como a administraçāo profissionalizada, um projeto arquitetônico bem-feito, o atendimento legal ou médico, o turismo bem organizado, a boa música ou a publicidade) é considerado ou não como algo de valor é uma questão totalmente subjetiva e dependente de cada cultura. O que é inquestionável é que por muitos anos os produtos da educação foram considerados como coisas boas e valorosas, e por isto mesmo geraram benefícios que todos apreciavam. É fácil imaginar como esta situação pode se reverter: pode haver gente demais oferecendo serviços e mercadorias por preços demasiado altos, gozando de privilégios e monopólios injustificáveis, injustos e sem relação definida com a qualidade dos produtos

${ }^{4}$ COLLINS, R. The credential society. New York, Academic Press, 1979; BOUDON, Raymond. A desigualdade de oportunidades. Editora da Universidade de Brasilia (primeira edição francesa de 1973); Pierre Bourdieu e Passeron. La Reproduction. Paris, Ed. de Minuit, 1970. 
que oferecem. Tudo isto $\epsilon$ subjetivo e dependente de valores, tradiçōes, e do marketing dos provedores de bens e serviços; suas conseqüências, no entanto, em termos da maneira pela qual as instituições educacionais e os setores educados funcionam em determinada sociedade, são muito reais, e afetam diretamente a capacidade de autonomia e auto-regulação de que as universidades podem dispor.

\section{Autonomia e Integraçăo}

Autonomia, ou auto-regulação, é uma característica constante de instituições baseadas na produção e transmissão de conhecimento, e ela funciona meIhor em duas condiçōes opostas. A primeira $\epsilon$ quando esta autonomia $e$ dada como 6́bvia, e ocorre de forma natural e não questionada. Isto se dá quando as universidades estāo bem integradas com o resto da sociedade, ou seja, quando seus professores são reconhecidamente competentes, seus produtos intelectuais reconhecidos como importantes, seus formados apreciados por sua competência, e seus custos não demasiadamente elevados. $O$ fato de os professores participarem diretamente da gestão das universidades, como na Europa, ou de existir um corpo especializado de administradores profissionais, como nos Estados Unidos, $€$ relativamente secundário desde este ponto de vista. A outra condição ocorre quando a sociedade $\epsilon$ de tal maneira segmentada que o mundo acadêmico dificilmente cruza seus caminhos com os de outros grupos sociais, e , por isto, não entram em colisão.

A autonomia se transforma em problema quando a integração com a sociedade se interrompe, ou quando as comunicaçóes entre os diversos setores se intensifica. A autonomia universitária em relaçảo à sociedade mais ampla $\epsilon$ hoje fortemente questionada na Europa Ocidental, por exemplo, por razōes de custo, e em nome do princípio democrático da igualdade de oportunidades. Na medida em que mais pessoas buscam as universidades, elas se tornam mais caras e dependentes do apoio e da aprovação externa de contribuintes, estudantes, legisladores, ministros, empregadores, planificadores. Cada um destes setores pressiona por melhores produtos, melhor uso do dinheiro público, e melhor atendimento a seus objetivos específicos, que freqüentemente não coincidem com os dos demais.

As universidades sempre lidaram com as pressões externas através da cooptação de personalidades públicas e ilustres, que recebem títulos honorários e são chamadas a tomar assento em comissóes consultivas importantes (mas quase sempre de pouca capacidade de decisão); pela criação de instituiçōes intermediarias, como o famoso University Grants Committee, na Inglaterra, ou os conselhos de ciência e educação em outras sociedades, incluindo, pelo menos em intenção, o Conselho Federal de Educação no Brasil; e pela colocação de seus próprios membros como conselheiros dos políticos e funcionários públicos, que são mais ou menos facilmente convencidos de sua incompetência para decidir as questōes do ensino superior e da pesquisa. Estes mecanismos são ge-

A autonomia universitária em relação à sociedade mais ampla é hoje

fortemente questionada na Europa Ocidental, por exemplo, por razōes de custo, e em nome do princípio democrático da igualdade de oportunidades. ralmente suficientes para proteger as universidades em tempos de relativa estabilidade e crescimento limitado. Não há por que imaginarmos que se trata, tão e simplesmente, de manipulação. Por estes meios, o público leigo e as autoridades terminam por conhecer mais de perto as universidades, e estas, através de suas lideranças mais significativas, encontram oportunidades de sentir melhor, e se ajustar gradualmente, às demandas cambiantes de seu ambiente externo.

Interferências externas se tornam particularmente perigosas quando vão além das tentativas de orientar as instituiçōes educacionais e se transformam em verdadeiros assaltos aos recursos e meios de que estas instituições dispōem. Políticos de inclinação antiintelectual podem decidir cortar recursos do ensino e transferi-los para fins mais populares, ou supostamente mais produtivos; insti- 
tuiçōes educacionais podem ser percebidas, e utilizadas, como mais uma fonte de empreguismo e clientelismo político; companhias privadas, ou institutos governamentais, podem roubar as universidades de seus cérebros, ou utilizar seus laboratórios e centros de pesquisa de acordo com seus interesses de curto prazo. Estas práticas dificilmente prosperam quando a legitimidade das instituições educacionais está bem definida; em outras circunstâncias, no entanto, seus efeitos podem ser devastadores.

Pressóes externas coincidem, freqüentemente, com conflitos internos. Dizem que as primeiras universidades italianas eram totalmente controladas pelos estudantes, que pagavam os professores e, por isto, os contratavam ou demitiam a seu bel-prazer. Se isto de fato ocorreu, não deve ter durado muito. Os professores eram geralmente mais velhos e mais sábios que os estudantes, e agiam com a autoridade da Igreja e das famílias. Conflitos entre professores e estudantes, no entanto, são tão antigos quanto as próprias universidades, e de alguma maneira fazem parte de um fenômeno muito mais geral, que é o dos conflitos intergeracionais.

Ensinar em uma universidade pode significar coisas muito distintas para pessoas diferentes - uma atividade de tempo parcial para um advogado ou médico, um envolvimento integral com o ensino e a pesquisa para um cientista, um simples emprego para um professor. Cada um destes profissionais tem sua própria maneira de vivenciar e entender sua atividade, e a instituição na qual ela se desenvolve. Nas universidades de pesquisa dos países anglo-saxōes, o que predomina é o professor-pesquisador, que define os padrōes e os modelos para o resto; nas universidades latino-americanas mais tradicionais, o que predomina é o profissional liberal que ensina em tempo parcial; nos grandes sistemas de educação de massas das sociedades modernas, o que predomina é o professor contratado em regime de tempo integral para dar aulas, que não é nem um profissional liberal como os velhos catedráticos, nem um cientista pesquisador'. A coexistência de pelo menos estes três tipos de personagem tão diferentes nas mesmas instituições, e desempenhando aparentemente os mesmos papéis, é uma fonte óbvia de tensão, que ocorre principalmente quando se tenta enxertar ao mesmo tempo, como foi no caso do Brasil, algumas características das universidades de pesquisa, e outras do ensino superior de massas, em organizaçóes acadêmicas tradicionais.

Os estudantes são o segundo elemento importante nas disputas de poder dentro das instituições acadêmicas. Sendo os destinatários mais óbvios dos serviços acadêmicos, eles se sentem naturalmente no direito de fazer prevalecer suas vontades ${ }^{6}$. A questão importante, naturalmente, é saber em que condiçōes esta sensação difusa se traduz em ação efetiva. A experiência de muitos países parece sugerir que a politizaçāo e participaçāo estudantil é mais alta quando os estudantes sāo oriundos da elite, mas suas oportunidades de obter posiçōes de prestígio e autoridade depois de formados são vistas como limitadas. $O$ oposto ocorre quando as perspectivas ocupacionais para os estudantes de elite são promissoras, ou quando o recrutamento é ampliado para incluir estudantes de origem social menos privilegiada. Nestes casos, há uma sensação de realização pessoal que em geral reduz a motivaçăo que o estudante possa ter em se envolver em atividades coletivas ligadas ao meio no qual ele se encontra a título

5 É curioso como a língua portuguesa não contempla a distinção, que existe, por exemplo, em inglês, entre o professor e o teacher ou lecturer, que serve exatamente para acentuar a distinção que estamos tratando de fazer. No Brasil, somos todos professores.

6 Veja a respeito LEVY, Daniel. Student politics in contemporary Latin America. Canadian Journal of Political Science. 14 (2): 353-376, 1981; e ALTBACH, Phillip G. Student politics in the Third World. Higher Education 13: 633-655, 1984.
A experiência de muitos países parece sugerir que a politização e participação est udantil e mais alta quando os estudantes são oriundos da elite, mas suas oportunidades de obter posiçōes de prestigio e antoridade depois de formados são vistas como limitadas. 
temporário. É possível especular, a partir destas constataçōes, a respeito dos prováveis efeitos da massificação do ensino superior sobre a politização estudantil. Em geral, na medida em que mais pessoas são trazidas para as instituições educacionais, poderemos esperar que sua capacidade de mobilização diminua, e isto parece ter acontecido em contextos tão diferentes quanto, por exemplo, o Brasil e os Estados Unidos nos últimos vinte anos. Por outro lado, existe um novo tipo de mobilizaçāo estudantil nas sociedades modernas que parece estar relacionado com os fenômenos de cultura de juventude que estão ocorrendo nas sociedades mais industrializadas. Um de seus componentes $\epsilon$ o desemprego estrutural dos jovens, e a extensão da faixa etária considerada como de juventude até próximo dos 30 anos, o que gera todo um novo conjunto de conflitos intergeracionais que se utilizam das instituições de ensino superior como campo de batalha.

Um último participante das disputas de poder dentro das instituições de ensino superior são os funcionários. A complexidade crescente destas instituiçōes tem levado, em muitas partes, ao desenvolvimento de uma nova profissão, a dos administradores universitários e educacionais, que têm suas próprias idéias a respeito de seu papel, e sua necessidade de reconhecimento, poder e autoridade. Mesmo quando este tipo de desenvolvimento não ocorre, funcionários administrativos são cada vez mais numerosos, se organizam em associações e sindicatos profissionais, e clamam por sua fatia do poder.

\section{Tensỏes e Reformas}

Em última análise, as tensōes que ocorrem dentro dos sistemas de ensino superior, e em sua relação com a sociedade mais ampla, dependem basicamente de se a sociedade está expandindo ou não suas oportunidades ocupacionais, se ela está ou não submetida a pressões demográficas, e se o sistema educacional está funcionando como canal efetivo de mobilidade social ou, ao contrário, de resistência contra novos grupos sociais emergentes. Na Europa - e provavelmente também no. Japão - a expansão do ensino superior ao final do século XIX e início deste proporcionou um espaço para grupos ascendentes que não tinham como ser absorvidos com facilidade pelo setor industrial, mas puderam se engajar em um processo modernizador, ou civilizatório, que deu um destino socialmente significativo a suas energias. Existe um claro paralelo entre a modernização das instituições de ensino nestas sociedades e o processo que Barrington Moore ${ }^{7}$ descreveu em relação à modernização da agricultura no surgimento das democracias modernas. Em muitas sociedades, não somente a agricultura não se modernizou, como que seus sistemas educacionais também permaneceram fechados, levando, em ambos os casos, a tensões potencialmente explosivas.

A politização tradicional das universidades latino-americanas $e$ um bom exemplo desta condição. As sociedades latino-americanas sempre foram muito segmentadas, e suas instituições de ensino superior eram provavelmente adequadas, até $o$ início deste século, para dar a suas elites a quantidade limitada de educação formal que elas desejavam. Tensões começaram a surgir, no entanto, quando novos grupos sociais - filhos de imigrantes, ou de classes médias incipientes nas cidades - começaram a entrar no sistema educacional e perceber que estas instituiçōes estavam demasiadamente rigidificadas para expandir e assumir novos papéis.

Nas primeiras décadas deste século, muitos países latino-americanos foram sacudidos pelo que ficou conhecido como o "Movimento da Reforma", que se iniciou na cidade de Córdoba, Argentina, em 1918. Ao lermos os do-

7 MOORE, B. Social origins of dictatorship and democracy: lord and peasant in the making of the modern world. Boston, Beacon Press, 1966. 
cumentos $^{8}$ e proclamaçóes associados ao movimento, dois àspectos chamam logo a atenção. $O$ primeiro é a condenação veemente da qualidade do ensino, a denúncia de que as universidades latino-americanas haviam deixado de cumprir seu papel central de portadoras do conhecimento. A segunda é a idéia de que só os estudantes poderiam mudar esta situação. Na realidade, a Reforma não consagrou o governo das universidades pelos estudantes, mas sim a divisăo tripartite dos órgãos de governo entre estudantes, professores e ex-alunos, os quais deveriam se inscrever junto às universidades para eleger seus representantes (não há evidência de que os ex-alunos jamais tenham chegado a desempenhar um papel muito significativo). Na conturbada história do Movimento da Reforma, os conflitos entre estudantes, professores e autoridades governamentais eram freqüentemente traduzidos em termos político-partidários, gerando muitas vezes lideranças de grande projeção nacional e internacional, como Alfredo Palácios, na Argentina; Haya de la Torre, no Peru; Raul Roa, em Cuba e Rómulo Betancourt, na Venezuela. As demandas por autonomia resultaram no estabelecimento de uma tradiçāo de extraterritorialidade para as cidades universitárias em muitos países latino-americanos, dando aos estudantes e professores direitos e privilegios com os quais os cidadãos comuns dificilmente sonhariam. Estes privilégios poderiam ser interpretados como indicando o sucesso do Movimento, levando ao reconhecimento e prestígio públicos das universidades. $O$ mais provável, no entanto, é que eles expressem simplesmente uma trégua temporária entre grupos antagônicos de elite, muitas vezes rompida por confrontações violentas e derramamentos de sangue.

As universidades latino-americanas parecem ter levado ao extremo um tipo específico de auto-regulação e autonomia, baseado essencialmente na capacidade de mobilização política, e não na ocupação efetiva de uma posição de centralidade entre as instituiçōes de geração e transmissão de conhecimento em suas sociedades. As razōes históricas para isto são muitas, e impossíveis de apresentar aqui. Mais importantes, de qualquer forma, são suas conseqüências. Uma comparação sistemática entre os processos de modernização das universidades na América Latina, Japão, Índia, África, a Rússia do século XIX e a Europa Ocidental traz ensinamentos preciosos ${ }^{9}$. Em nenhum país as universidades deixaram de mudar. Em todos os casos elas tiveram que abrir espaço para novas idéias, novas geraçōes, e em muitos casos compartir o poder com novos grupos. Somente em alguns casos, no entanto, elas conseguiram se transformar de maneira tal que pudessem reter sua função histórica de centros geradores e transmissores de conhecimento. Em outros, elas terminaram ocupadas por outros grupos, com outros interesses, e nunca conseguiram ir muito além de suas funções clássicas de agentes de legitimação de posições de status e poder adquiridas por meios que têm pouco a ver, na realidade, com o conhecimento enquanto tal.

\section{Novas Funçōes para Novos Tempos}

A experiência histórica indica que a vitalidade das instituições universitárias, como núcleo gerador de novas idéias, conhecimentos e valores, tem estado

8 Os documentos referentes à reforma de Córdoba estão reunidos em CUENO, Dardo. La reforma universitaria (1918-1930). Caracas, Biblioteca Ayacucho, 1976. Para uma visão geral, ver GIAMBIAGI, Mário. O movimento da reforma universitária de 1918 na Argentina - Aspectos históricos e projeções. Centro Brasileiro de Pesquisas Físicas, série Ciência e Sociedade, 1983. Ver também PORTANTIERO, J.C. Estudiantes y Politica en America Latina, 1918-1938. El Proceso de la Reforma Universitaria. México, Siglo XXI, 1978.

9 Sobre a India, Japão, América Latina e Turquia, veja SCHWARTZMAN, S. A Questão da Universidade. In: Ciência, Universidade e Ideologia: a política do conhecimento. Rio de Janeiro, Zahar, 1980. cap. 4. 
e deve estar intimamente relacionada com sua integração relativamente frouxa (ou, em outros termos, com sua relativa independência) em relação às fontes de liderança e dominação econômica, política e religiosa que existem em todas as sociedades. A universidade bem-comportada, que funcionasse de maneira integrada e sem tensões com outros setores da sociedade, seria quase certamente uma universidade burocratizada, desmotivada, sem vida e, em última análise, sem maior relevância.

É importante também que, neste processo de competição com outros setores da sociedade, as universidades nāo terminem vitoriosas e percam, sem sentir, sua identidade própria. É próprio da universidade não ser a fonte de conhecimentos sagrados ou ideológicos, nem do poder econômico, nem do poder político; ela deixa de ser universidade quando se transforma em Igreja, empresa ou partido. Encontrar seu espaço próprio, não se submeter nem se descaracterizar, $\epsilon$ a chave para sua permanência e relevância.

Finalmente, os sistemas universitários modernos têm em si o germe da universidade clássica, mas também muitas outras coisas que têm pouco a ver com ela. Por isto mesmo, eles são necessariamente instáveis e contraditórios, e sujeitos a um processo constante de disputa e competição. Esta $€$ uma situação inevitável, que não pode ser corrigida sem que algumas das funções mais importantes dos sistemas educacionais modernos sejam sacrificadas. O que $e$ importante, aqui, $\epsilon$ aprendermos a conviver com a variedade, a diferenciação e a pluralidade de objetivos e princípios que são inerentes aos sistemas sociais modernos. Com o surgimento do ensino superior de massas, dramatizado pelas mobilizaçōes estudantis de 1968, a questão da reforma universitária voltou à ordem do dia em todo o mundo. A experiência acumulada desde entāo parece sugerir que os sistemas de ensino superior atuais são grandes demais, politizados demais para poderem ser alterados por grandes projetos reformadores, que, ou são bloqueados por interesses afetados, ou se frustram em sua implementação ${ }^{10}$. Isto não significa, no entanto, que não exista espaço para mudança; mas ela não pode se dar a partir de um amplo consenso a respeito de um novo papel para o sistema universitário, e sim da diferenciação progressiva de suas funçôes, e no atendimento particularizado a suas diferentes clientelas.

É a partir destas perspectivas que podemos pensar melhor a crise de legitimidade que hoje atinge nossas instituiçōes de ensino superior. Como elas se desenvolverão nos próximos anos, que tipo de relações estabelecerão com ou-

A universidade bem-comportada, que funcionasse de maneira integrada e sem tensōes com outros setores da sociedade, seria quase certamente uma universidade burocratizada, desmotivada, sem vida e, em última análise, sem maior relevância. tras instituições produtoras e difusoras de conhecimento nas sociedades modernas, em que medida permanecerão ou não como lugares privilegiados da geração e expansão da fronteira intelectual e científica, de que forma poderão se ajustar às múltiplas demandas que recebem sem perda de autonomia e responsabilidade - e, finalmente, em que medida sua autonomia será fruto de seu prestígio, ou de sua alienação - são estas as questōes que deveremos observar, e que definirāo o futuro desta instituição milenar. A sina da universidade, se podemos utilizar esta figura, é estar sempre descontente com suas limitaçōes, sem perder, no entanto, sua identidade, forjada na evoluçăo das sociedades modernas nos últimos séculos. Na medida em que ela possa se manter fiel a esta sina, ela será, ainda por muito tempo, um fator de perturbação, discussão, eventualmente conflito - mas também de esperança para um mundo melhor.

10 CERYCH, L. e SABATIER, P. Great expectations and mixed performance - The implementation of higher education reforms in Europe. Trentham Books, European Institute of Education and Social Policy, 1986.

Simon Schwartzman é diretor científico do NUPES (Núcleo de Pesquisas sobre Ensino Superior) da USP e professor-visitante do IEA no período de março de 1988 a março de 1989. 